\title{
Steroid treatment in patients with acute respiratory distress syndrome: a systematic review and network meta-analysis
}

\author{
Shodai Yoshihiro ${ }^{1} \cdot$ Takashi Hongo $^{2} \cdot$ Shingo Ohki $^{3} \cdot$ Tadashi Kaneko $^{4} \cdot$ Junichi Ishikawa $^{5} \cdot$ Shoichi Ihara ${ }^{6}$. \\ Shunsuke Taito $^{7} \cdot$ Masahiko Sakaguchi $^{8} \cdot$ Tomoaki Yatabe $^{9}$
}

Received: 18 June 2021 / Accepted: 20 October 2021 / Published online: 10 November 2021

(c) The Author(s) under exclusive licence to Japanese Society of Anesthesiologists 2021

\begin{abstract}
Purpose Although the most recent systematic review and meta-analyses on acute respiratory distress syndrome (ARDS) have shown that the use of steroids decreases mortality in adult patients, its benefits and risks may differ depending on the type and dosage of the steroid. Therefore, we conducted a network meta-analysis (NMA) to compare the differences in the efficacy among different doses and types of steroids.

Methods We searched MEDLINE, CENTRAL, ICHUSHI, ClinicalTrials.gov, and WHO ICTRP databases from the earliest records to March 2021 for randomized control trials, which compared steroids with placebo or conventional therapy for ARDS. Using the random-effects model, we compared various categories of steroids (high-dose methylprednisolone, low-dose methylprednisolone, hydrocortisone, dexamethasone, and no steroid) concerning hospital mortality, incidence of infection, and ventilator-free days (VFD).

Results We analyzed nine studies involving adult patients $(n=1212)$. Although there were no significant differences between the groups in terms of the mortality and incidence of infection, the number of VFD were greater when using low-dose methylprednisolone than when not using any steroids (Mean difference: 6.06; 95\% confidence intervals: [2.5, 10.5]). Moreover, the rank probability showed that low-dose methylprednisolone might be the optimal treatment, whereas using no steroid or high-dose methylprednisolone may be inferior to other treatments in terms of mortality, infection, and VFD.

Conclusion This NMA suggested that the effect of steroids on the outcome in patients with ARDS might depend on the type of the steroid drug administered. Moreover, further studies are needed to identify the optimal type and dosage.
\end{abstract}

Keywords Systematic review $\cdot$ Critical care $\cdot$ Respiratory insufficiency $\cdot$ Steroids $\cdot$ Network meta-analysis

Tomoaki Yatabe

yatabe.tomoaki@katch.ne.jp

1 Pharmaceutical Department, JA General Hospital, Hiroshima, Japan

2 Department of Emergency, Okayama Saiseikai General Hospital, Okayama, Japan

3 Department of Emergency and Critical Care Medicine, Graduate School of Biomedical and Health Sciences, Hiroshima University, Hiroshima, Japan

4 Emergency and Critical Care Center, Mie University Hospital, Tsu, Japan

5 Emergency and Critical Care Medical Center and Pediatric Emergency Medicine, Osaka City General Hospital, Osaka, Japan
6 Department of Respiratory Medicine, Osaka Police Hospital, Osaka, Japan

7 Division of Rehabilitation, Department of Clinical Practice and Support, Hiroshima University Hospital, Hiroshima, Japan

8 Department of Engineering Informatics, Osaka Electro-Communication University, Neyagawa, Japan

9 Department of Anesthesiology and Intensive Care Medicine, Nishichita General Hospital, 3-1, Nakanoike, Tokai-shi, Tokai, Aichi 477-8522, Japan 


\section{Introduction}

Acute respiratory distress syndrome (ARDS) is defined as acute respiratory failure due to non-hemodynamic pulmonary edema caused by inflammatory cytokines, and it is associated with a high mortality rate [1,2]. Inflammatory cytokines were modulated by a pro-inflammatory transcription factor, nuclear factor-kappa B (NF-кB) [3, 4]. Steroids are expected to treat ARDS by attenuating NF- $\kappa B$ by the action of the glucocorticoid receptor $\alpha$.

The most recent systematic review and meta-analyses (SR/MA) on ARDS have shown that the use of steroids decreases mortality and increases ventilator-free days (VFD) [5]. Another recent SR/MA suggested that early and longer administration of steroids in patients with ARDS might reduce mortality [6]. In these SR/MA, different types and dosages of steroids, such as high-dose methylprednisolone [7], low-dose methylprednisolone [8-10], hydrocortisone [11], and dexamethasone [12, 13] were used. In addition, the biological half-life and anti-inflammatory potency of steroids vary depending on its type. Though the differences in the type and dosage of steroids might affect outcomes, the optimal steroid regimen in terms of the benefit-risk ratio in ARDS remains unclear because these pairwise SR/MA assessed over all efficacy and outcomes of steroid by comparing groups of patients that did and did not use steroids.

We hypothesized that the steroid type influences the outcome in ARDS patients and sought to verify this by performing a network meta-analysis (NMA). Therefore, we conducted this systematic review and NMA to identify the optimal steroid therapy among patients with ARDS.

\section{Methods}

\section{Protocol}

We conducted this SR according to the Preferred Reporting Items for Systematic review and Meta-Analyses extension statement for reviews incorporating network meta-analyses (Online Resource 1) [14].

\section{Eligibility criteria}

We included randomized control trials (RCTs) that compared steroids for established ARDS. We did not search for quasirandomized studies, cohort studies, case-control studies, and case series. ARDS was diagnosed according to the American European Consensus Conference (AECC) [15] definition (1994) or Berlin (2012) diagnostic criteria [16]. During our search for studies published before the establishment of the
AECC, we included patients with acute respiratory failure, which was defined as follows: an acute onset of hypoxemia with a $\mathrm{PaO}_{2}$ to $\mathrm{FiO}_{2}$ ratio $(P / F$ ratio) of $\leq 200 \mathrm{mmHg}$, bilateral noncardiogenic pulmonary edema, no clinical evidence of increased left atrial hypertension, and a pulmonary artery wedge pressure $\leq 18 \mathrm{mmHg}$ in the presence of a pulmonary artery catheter. Patients who had been previously treated with corticosteroids and immunosuppressive drugs or had cardiogenic pulmonary edema and hypercapnia without hypoxia were excluded. As we investigated the effects of steroids in established ARDS patients, we excluded patients with oxygenation of $200<P / F$ ratio $\leq 300$ and no ventilation. We also excluded patients who were administered inhaled steroids because of the limited effects on the lungs without collapse.

We categorized interventions according to the received four types of steroids based on previous studies [7-10, 12, $13,17,18]$ and compared the results obtained from the following five groups: high-dose methylprednisolone, lowdose methylprednisolone, hydrocortisone, dexamethasone, and no steroid. We defined high-dose methylprednisolone as $\geq 1000 \mathrm{mg} /$ day on the first day, $1000 \mathrm{mg} /$ day on the second and third day, and tapering from the fourth day. We defined low-dose methylprednisolone as a methylprednisolone dose of $1.0-2.0 \mathrm{mg} / \mathrm{kg} /$ day after loading dose of $1.0-2.0 \mathrm{mg} / \mathrm{kg} / \mathrm{day}$ from the first day to 14 th day, which was administered for at least 3 weeks with tapering. We defined hydrocortisone as 200-300 mg/day for 7 days. We defined dexamethasone as any dosage for 10 days. We defined no steroid as a placebo or conventional therapy.

The primary outcome of this SR was hospital mortality. The secondary outcomes were incidence of infection and number of VFD. When data on hospital mortality were not available, we collected data on the longest mortality within 28-60 days after randomization.

\section{Information sources, search strategy, study selection, and data collection process}

The searched databases were MEDLINE via PubMed, the Cochrane Central Register of Controlled Trials (CENTRAL), and Igaku Chuo Zasshi (ICHUSHI). The ICHUSHI Web is the largest database of Japanese medical journals, containing approximately 10 million manuscripts from 6000 journals. We comprehensively searched these databases for relevant studies published from the earliest records to March 2021. We also searched for ongoing and unpublished trials in the following trial registers: ClinicalTrials.gov and the World Health Organization International Clinical Trials Platform Search Portal (WHO ICTRP) in March 2021. The list of search terms is shown in Online Resource 2. Additionally, we manually searched reference lists of included studies, 
previous SR/MA [6, 19-22], and articles citing these studies (based on citation information from the Web of Science).

When the screened records did not contain the necessary information, we inquired the authors for details. Two or more reviewers independently screened the titles and abstracts of the studies in the first screening. Articles included in the first screening were assessed for eligibility according to the inclusion criteria by reading the full texts. When the reviewers disagreed with the inclusion, conflicts were resolved by consensus. Two or more reviewers independently extracted data from full manuscripts. We extracted data pertaining to study characteristics such as study design, locations of the study center, sample size, information of participants (age, diagnostic criteria, and main etiology of ARDS), interventions, comparisons, low tidal ventilation as conventional therapy, and outcomes. We contacted the authors of the studies to collect sufficient information if necessary. The relevant data of the included studies were summarized using Microsoft Excel and Cochrane Statistical Package Review Manager (version 5.3; Cochrane Collaboration, Copenhagen, Denmark).

\section{Geometry of the network}

We constructed network plots for each outcome in this NMA. Each node corresponded to a treatment strategy. The edge presented direct comparisons between interventions and comparators and added to the number of included studies.

\section{Abstraction of data and assessment of the risk of bias}

Two or more reviewers independently classified the risk of bias for each included study as high, low, or unclear. We assessed the following seven domains for risk of bias using the Cochrane risk of bias assessment tool [23]: random sequence generation, allocation concealment, blinding of participants and personnel, blinding of outcome assessor, incomplete data outcome, selective reporting, and other bias. When reviewers disagreed with the decision on the risk of bias, conflicts were resolved by discussing with a third reviewer.

\section{Data synthesis}

We conducted a pairwise meta-analysis using the randomeffects method to assess for direct associations between interventions and outcomes. We integrated the dichotomous variables as risk ratios (RR) with $95 \%$ confidence intervals (CI) and continuous variables as mean differences (MD) with $95 \%$ CI. We assessed heterogeneity using visual inspection of forest plot and $I^{2}$ statistics. We assessed indirectness by checking patient characteristic of each included studies. We assessed publication bias by checking the number of studies that had not been published on ClinicalTrials.gov and WHO ICTRP.

We conducted an NMA using the Bayesian randomeffects method to derive direct and indirect estimates comparing all interventions and comparisons. We integrated the dichotomous variables as odds ratios (OR) with $95 \%$ credible intervals (CrIs) and continuous variables as MD with 95\% CrIs. We assessed intransitivity by checking patient characteristic of each direct comparison as the source for indirect estimates. We assessed imprecision by each $95 \%$ CrIs crossing clinically important intervals of OR defined as $0.8-1.25$. We assessed incoherence using the node-splitting method [24]. We derived rank probability for each intervention and comparison from the results of the NMA within a Bayesian framework and decided treatment hierarchy using surface under the cumulative ranking curve (SUCRA) [25].

We assessed the certainty of evidence $(\mathrm{CoE})$ for each estimate using the Grades of Recommendation, Assessment, Development, and Evaluation Working Group (GRADE) approach for NMA [26, 27]. First, we assessed the CoE for direct estimate using five considerations (risk of bias, heterogeneity, indirectness, publication bias, and imprecision). Second, we assessed the CoE for the indirect estimate by considering the $\mathrm{CoE}$ for the direct estimate of the common comparator related to the indirect estimate and using two considerations (intransitivity and imprecision). Finally, we assessed the $\mathrm{CoE}$ for network estimate by considering the $\mathrm{CoE}$ for direct and indirect estimates and using two considerations (incoherence and imprecision).

We defined statistical significance as 95\% CIs and CrIs that did not cross the value 1.0. We used the Cochrane Statistical Package Review Manager (version 5.3; Cochrane Collaboration, Copenhagen, Denmark) for the pairwise metaanalysis. We performed NMA using JAGS and R (version 4.0.4; The R Foundation, Wien, Austria) software, whereas the rjags and gemtc packages were used for the Bayesian approach. We then created the table showing the summary of findings [28].

\section{Results}

\section{Study selection}

A flow diagram of this study is shown in Fig. 1. After eliminating the duplicates, we assessed 2810 records through databases and other source searches. We excluded 2714 records by screening the titles and abstracts and 96 records using full texts. On assessing the remaining 54 records for eligibility, we found two articles [8, 29] published from the same study. Subsequently, we identified 15 eligible studies. 
Fig. 1 Flow diagram of this study. CENTRAL Cochrane Central Register of Controlled Trials, ICHUSHI Igaku Chuo Zasshi, ICTRP World Health Organization International Clinical Trials Platform Search Portal

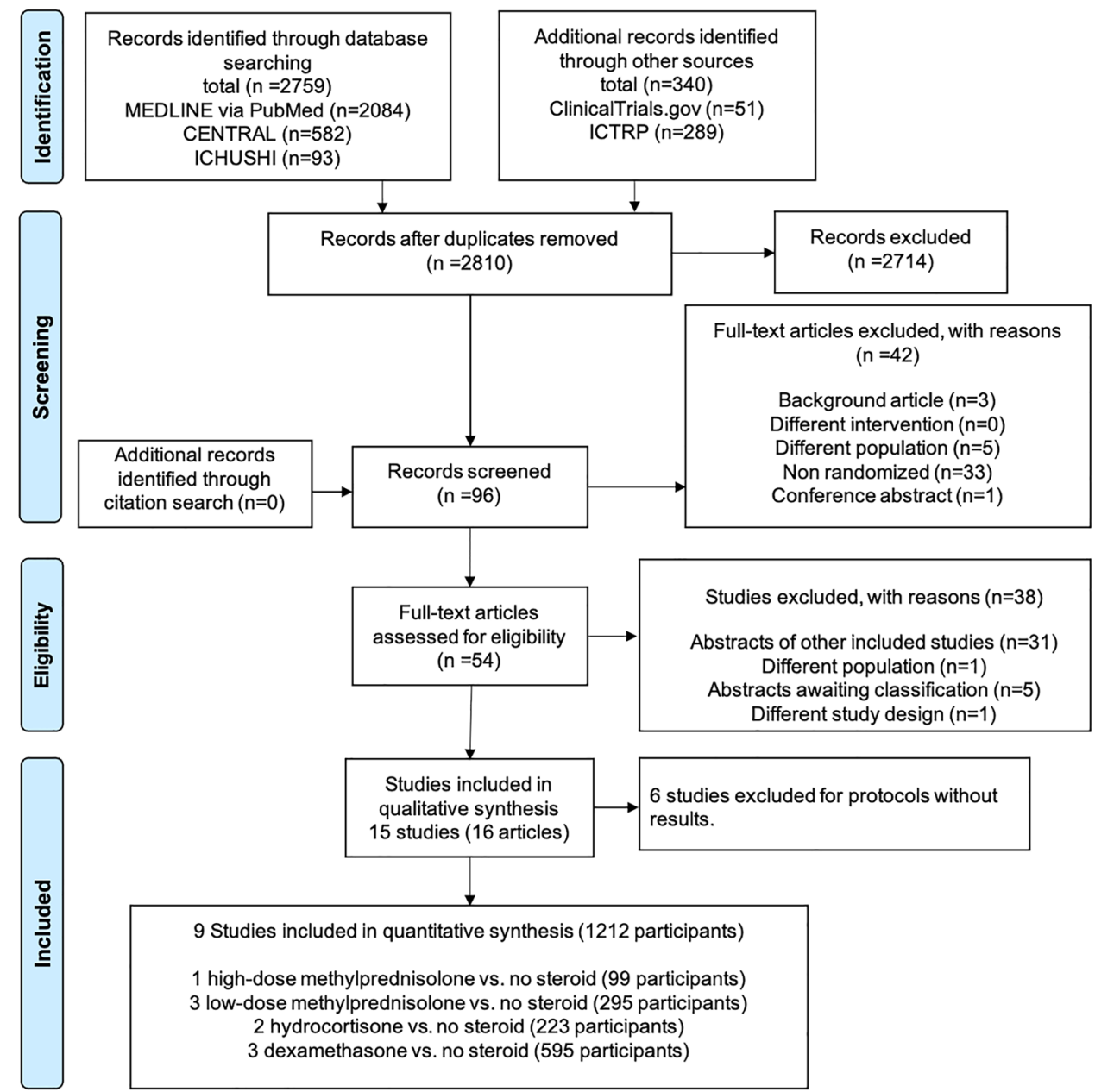

Among the 15 eligible studies, we excluded six studies with unpublished outcomes (Online Resource 3). Two of the six excluded studies had completed recruitment, but we did not get a reply from the authors regarding the outcome data, proportion of ARDS, and diagnostic criteria for ARDS. Finally, we included nine studies $(n=1212)$ for quantitative synthesis, the details of which are provided in Table 1. The network of eligible comparisons for the meta-analysis is shown in Fig. 2.

\section{Study characteristics}

One study compared high-dose methylprednisolone with placebo [7]. Three studies compared low-dose methylprednisolone with placebo [8-10], two studies compared hydrocortisone with placebo $[11,30]$, and three studies compared dexamethasone with no steroid and were not used as placebo $[12,13,31]$. Direct pairwise comparisons are provided in Online Resource 4.

The most common etiology was pneumonia $57.1 \%$ $(692 / 1,212)$. Ventilation strategy of six studies was low tidal ventilation [9, 11-13, 31, 32]. We grouped 28-day mortality for two studies [12, 30], 60-day mortality for three studies [9, 11, 31], and 45-day mortality for one study [7] to assess hospital mortality. VFD were measured in eight studies, while VFD of one study [8] were obtained from the author. We converted $95 \%$ CI of VFD to a standard deviation in one study [12]. Data on infections were collected from nine studies. One study [13] assessed new infections in the ICU, while another study [31] assessed pneumonia in the ICU. The observation period for infection was 28 days in two studies $[9,12], 7$ days in one study [7], 1 year in one study [10], and up to discharge in one study [11]. Two studies [8, 30] did not report the observation period for the infection. Two studies $[12,31]$ did not use a placebo and had unplanned termination of the recruitment of participants. We received no reply about the data on 60-day mortality and infection from the authors of one of the studies [31].

\section{Risk of bias and CoE}

We assessed the overall risk of bias of four studies [7-9, 11] as low, that of four studies [10, 12, 30, 31] as unclear, and that of one study [13] as high using the Cochrane risk of bias 


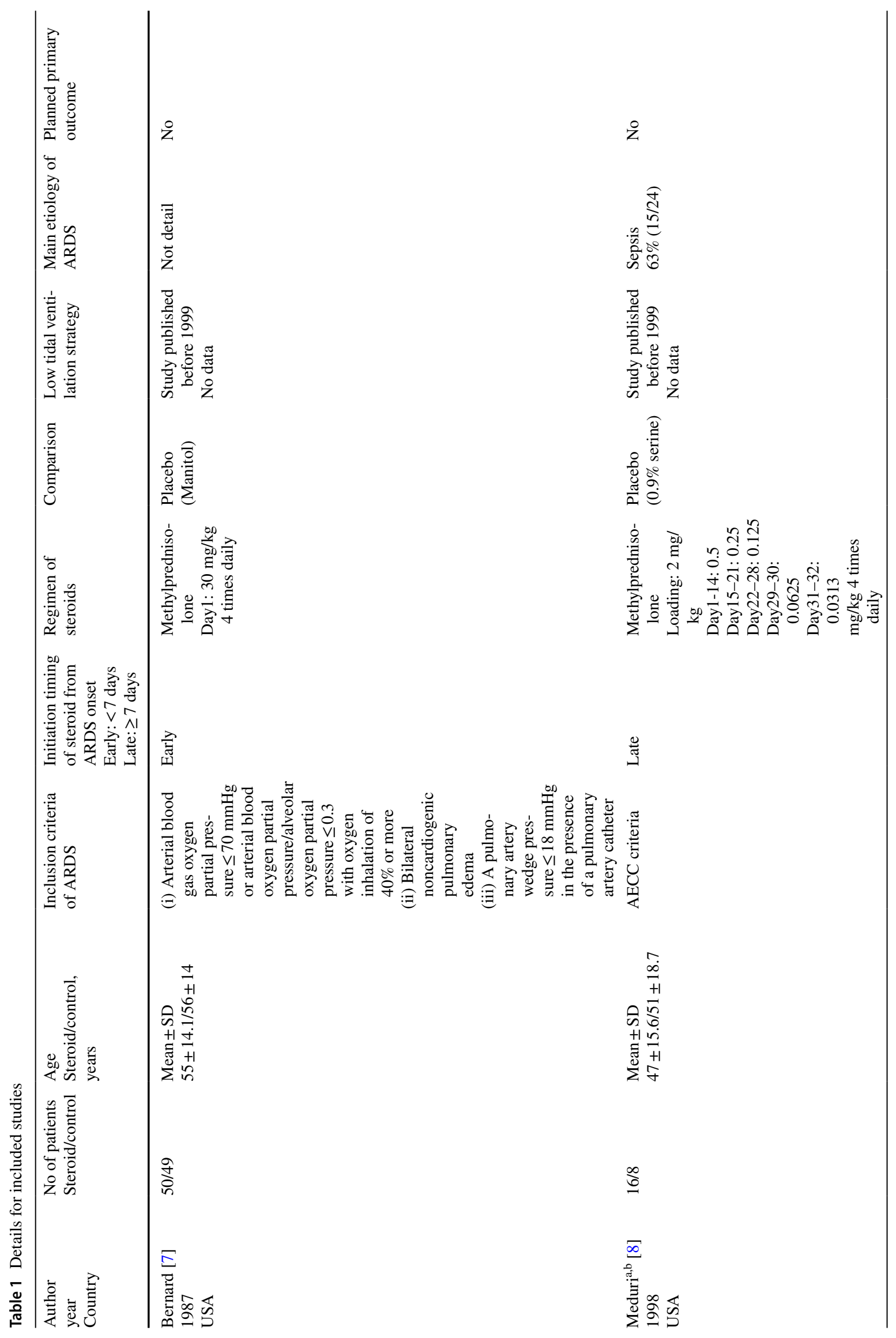




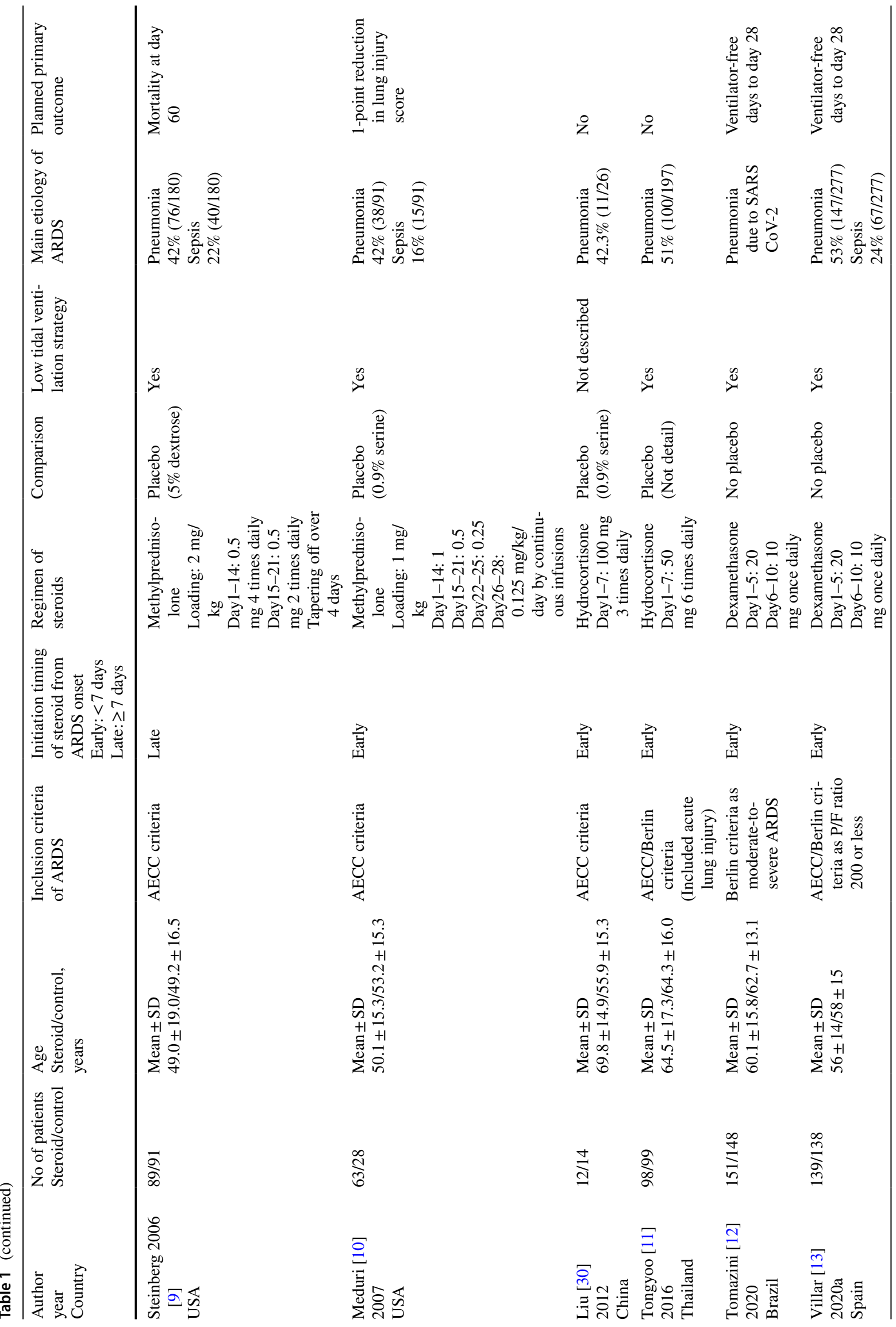




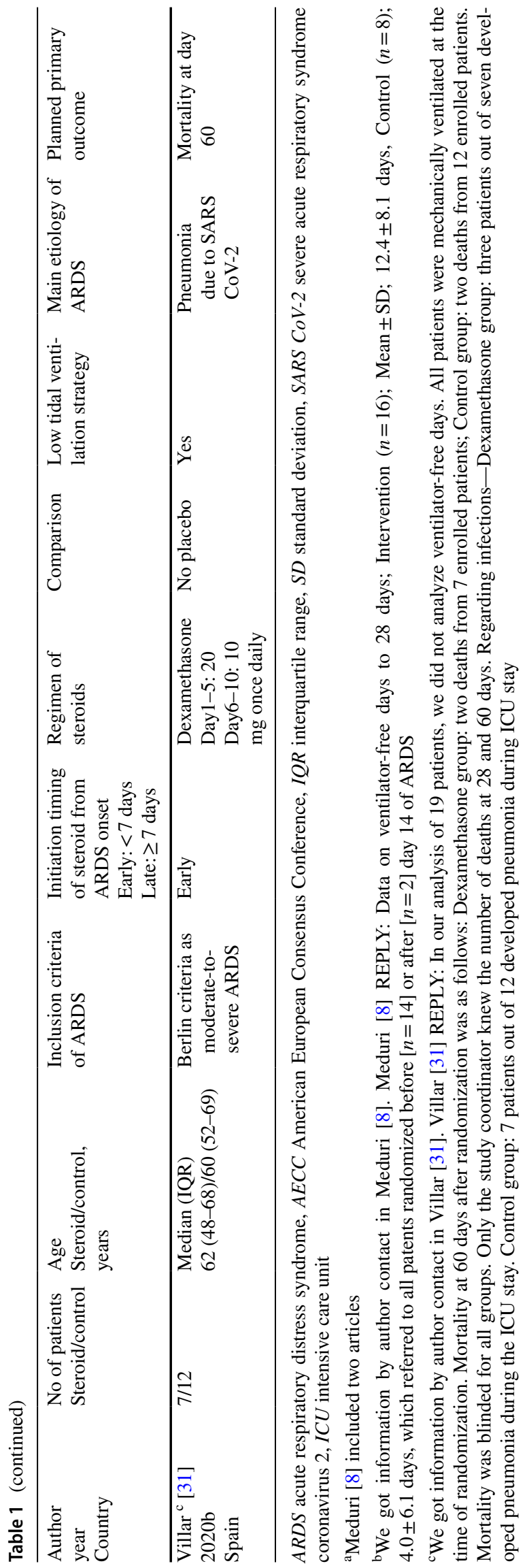

assessment tool. Domains of risk of bias for each outcome are shown in Table 2. We showed processes of assessment for $\mathrm{CoE}$ in Online Resource 5, and the results concerning $\mathrm{CoE}$ in Online Resource 6. As we could not analyze direct comparisons for each steroid, we could not assess incoherence between direct and indirect estimates.

\section{Hospital mortality}

Network estimate for hospital mortality was created from nine RCTs including 1212 patients (Table 3). High-dose methylprednisolone, low-dose methylprednisolone, hydrocortisone, and dexamethasone were not associated with a reduction in hospital mortality compared with no steroid. Using dexamethasone as a reference comparator, there was no statistical difference in the association with hospital mortality when comparing high-dose methylprednisolone (OR 1.16 95\% CrI [0.08, 12.9], 36 more patients per 1000 patients, CoE: very low). Low-dose methylprednisolone (OR $0.6695 \%$ CrI [0.07, 3.04], 95 less patients per 1000 patients, CoE: very low), and hydrocortisone (OR 0.72 95\% CrI [0.06, 4.35], 76 less patients per 1000 patients, CoE: very low) were not associated with the reduction of hospital mortality compared with dexamethasone. Using hydrocortisone as a reference comparator, high-dose methylprednisolone (OR 1.62 95\% CrI [0.13, 31.0], 113 more patients per 1000 patients, CoE: very low) was not associated with increasing hospital mortality. There was no statistical difference in the association with hospital mortality when comparing low-dose methylprednisolone with hydrocortisone (OR $0.9395 \%$ CrI [0.11, 7.42], 16 less patients per 1000 patients, CoE: low). Using low-dose methylprednisolone as a reference comparator, high-dose methylprednisolone (OR 1.74 95\% CrI [0.18, 30.0], 118 more patients per 1000 patients, CoE: very low) was not associated with increasing hospital mortality. The rank probability of hospital mortality was in the order of low-dose methylprednisolone, hydrocortisone, dexamethasone, high-dose methylprednisolone, and no steroid (Fig. 3).

\section{Incidence of infection}

Network estimate for incidence of infection was created from nine RCTs including 1212 patients (Table 3). High-dose methylprednisolone, low-dose methylprednisolone, hydrocortisone, and dexamethasone were not associated with a reduction in the incidence of infection compared with no steroid Using dexamethasone as a reference comparator, high-dose methylprednisolone (OR 2.26 95\% CrI [0.55, 10.2], 174 more patients per 1000 patients, CoE: very low), and hydrocortisone (OR 1.32 95\% CrI [0.49, 3.84], 53 more patients per 1000 patients, CoE: very low) were not associated with increasing incidence of infection compared with 
Fig. 2 Network plot. A Hospital mortality B incidence of infection $\mathbf{C}$ Ventilator-free days. Each node corresponded to a treatment strategy. The edge presented direct comparisons between interventions and comparators and added to the number of included studies
A Hospital mortality

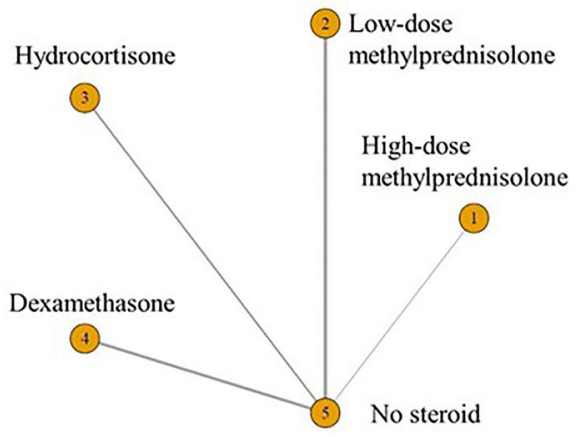

C Ventilator-free days

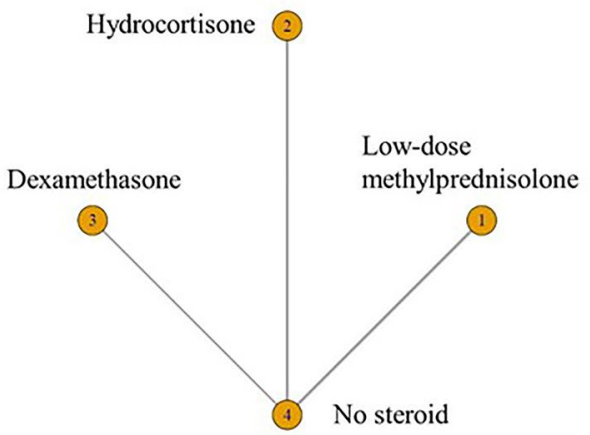

B Incidence of infection

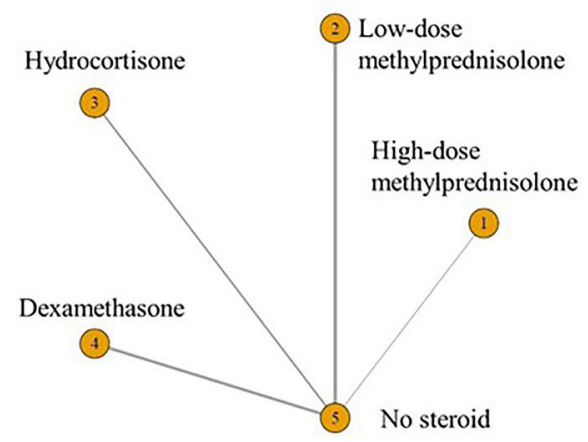

dexamethasone. There was no statistical association when the reduction of incidence of infection compared low-dose methylprednisolone with dexamethasone (OR 0.74 95\% CrI [0.32, 1.77], 49 less patients per 1000 patients, CoE: very low). Using hydrocortisone as a reference comparator, high-dose methylprednisolone (OR 1.73 95\% CrI [0.33, 8.45], 95 more patients per 1000 patients, CoE: very low) was not associated with increasing incidence of infection. There was no statistical association when the reduction of incidence of infection compared low-dose methylprednisolone with hydrocortisone (OR $0.5695 \% \mathrm{CrI}[0.19,1.60], 71$ less patients per 1000 patients, CoE: low). Using low-dose methylprednisolone as a reference comparator, high-dose methylprednisolone (OR 3.06 95\% CrI [0.70, 14.1], 272 more patients per 1000 patients, CoE: very low) was not associated with increasing incidence of infection. The rank probability of the incidence of infection was in that order of low-dose methylprednisolone, dexamethasone, hydrocortisone, no steroid, and high-dose methylprednisolone (Fig. 3).

\section{VFD}

Network estimate for VFD was created from seven RCTs including 1094 patients (Table 3). Low-dose methylprednisolone was associated with increasing VFD compared with no steroid (MD 6.00, 95\% CI [3.39, 8.61]; CoE: high).
Other comparisons with no steroid showed that the other treatments were not associated with increasing VFD. Using dexamethasone as a reference comparator, low-dose methylprednisolone (MD 2.40 95\% CrI [- 2.87, 8.70], CoE: very low) was not associated with increasing VFD. There was no statistical difference in association with VFD when hydrocortisone was compared with dexamethasone (MD - 1.54 95\% CrI [- 8.34, 4.87], CoE: very low). Using hydrocortisone as a reference comparator, low-dose methylprednisolone (MD 3.99 95\% CrI [- 1.90, 11.1], CoE: moderate) was not associated with increasing VFD. The rank probability of VFD was in the order of low-dose methylprednisolone, dexamethasone, hydrocortisone, and no steroid (Fig. 3).

\section{Discussion}

The present study revealed that although there were no significant differences in hospital mortality and incidence of infection among all comparisons, including steroids and no steroid, low-dose methylprednisolone resulted in a greater improvement of VFD compared with no steroid. Though the $\mathrm{CoE}$ of most comparisons was very low, the anticipated absolute effect and rank probability indicated that the effect of steroids on the outcome in ARDS patients might vary depending on the type and/or dose of steroids. 
Table 2 Risk of bias summary

\begin{tabular}{|c|c|c|c|c|c|c|c|}
\hline Study & $\begin{array}{l}\text { Random } \\
\text { sequence } \\
\text { generation }\end{array}$ & $\begin{array}{l}\text { Allocation con- } \\
\text { cealment }\end{array}$ & $\begin{array}{l}\text { Blinding for } \\
\text { participants and } \\
\text { personnel }\end{array}$ & $\begin{array}{l}\text { Blinding for } \\
\text { outcome asses- } \\
\text { sors }\end{array}$ & $\begin{array}{l}\text { Incomplete } \\
\text { outcome } \\
\text { data }\end{array}$ & $\begin{array}{l}\text { Selective } \\
\text { outcome } \\
\text { reporting }\end{array}$ & $\begin{array}{l}\text { Other sources } \\
\text { of bias }\end{array}$ \\
\hline \multicolumn{8}{|c|}{ a. Risk of bias summary of hospital mortality } \\
\hline Bernard 1987 [7] & Low risk & Low risk & Low risk & Low risk & Low risk & Unclear risk & Low risk \\
\hline Meduri 1998 [8] & Low risk & Low risk ${ }^{a}$ & Low risk ${ }^{a}$ & Low risk ${ }^{a}$ & Low risk & Unclear risk & Low risk \\
\hline Steinberg 2006 [9] & Low risk & Low risk & Unclear risk & Low risk & Low risk & Low risk & Low risk \\
\hline Meduri 2007 [10] & Low risk & Low risk & Low risk $^{a}$ & Low risk ${ }^{a}$ & Low risk & High risk $^{\text {a }}$ & Low risk \\
\hline Liu 2012 [30] & Unclear risk & Unclear risk & Unclear risk & Low risk & Low risk & Unclear risk & Low risk \\
\hline $\begin{array}{l}\text { Tongyoo } 2016 \\
\text { [11] }\end{array}$ & Low risk & Low risk & Low risk & Low risk & Low risk & Unclear risk & Low risk \\
\hline $\begin{array}{l}\text { Tomazini } 2020 \\
{[12]}\end{array}$ & Low risk & Low risk & High risk $^{b}$ & Low risk & Low risk & Low risk & Low risk \\
\hline Villar 2020a [13] & Low risk & Low risk & High risk ${ }^{\mathrm{b}}$ & Low risk & Low risk & High risk ${ }^{\mathrm{c}}$ & Low risk \\
\hline Villar 2020b [31] & Low risk & Low risk & High risk $^{\mathrm{b}}$ & Low risk & Low risk & Low risk & Low risk \\
\hline \multicolumn{8}{|c|}{ b. Risk of bias summary of incidence of infection } \\
\hline Bernard 1987 [7] & Low risk & Low risk & Low risk & Low risk & Low risk & Unclear risk & Low risk \\
\hline Meduri 1998 [8] & Low risk & Low risk ${ }^{\mathrm{a}}$ & Low risk ${ }^{\mathrm{a}}$ & Low risk ${ }^{\mathrm{a}}$ & Low risk & Unclear risk & Low risk \\
\hline Steinberg 2006 [9] & Low risk & Low risk & Unclear risk & Unclear risk & Low risk & Low risk & Low risk \\
\hline Meduri 2007 [10] & Low risk & Low risk & Low risk ${ }^{\mathrm{a}}$ & Low risk ${ }^{\mathrm{a}}$ & Low risk & High risk $^{\mathrm{a}}$ & Low risk \\
\hline Liu 2012 [30] & Unclear risk & Unclear risk & Unclear risk & Unclear risk & Low risk & Unclear risk & Low risk \\
\hline $\begin{array}{l}\text { Tongyoo } 2016 \\
\text { [11] }\end{array}$ & Low risk & Low risk & Low risk & Low risk & Low risk & Unclear risk & Low risk \\
\hline $\begin{array}{l}\text { Tomazini } 2020 \\
\text { [12] }\end{array}$ & Low risk & Low risk & High risk ${ }^{\mathrm{b}}$ & Unclear risk & Low risk & High risk ${ }^{\mathrm{c}}$ & Low risk \\
\hline Villar 2020a [13] & Low risk & Low risk & High risk ${ }^{b}$ & Low risk & Low risk & High risk ${ }^{\mathrm{c}}$ & Low risk \\
\hline Villar 2020b [31] & Low risk & Low risk & High risk ${ }^{\mathrm{b}}$ & Unclear risk & Low risk & Low risk & Low risk \\
\hline \multicolumn{8}{|c|}{ c. Risk of bias summary of ventilator-free days } \\
\hline Meduri 1998 [8] & Low risk & Low risk ${ }^{\mathrm{a}}$ & Low risk ${ }^{\mathrm{a}}$ & Low risk & Low risk & Unclear risk & Low risk \\
\hline Steinberg 2006 [9] & Low risk & Low risk & Unclear risk & Low risk & Low risk & Low risk & Low risk \\
\hline Meduri 2007 [10] & Low risk & Low risk & Low risk ${ }^{\mathrm{a}}$ & Low risk & Low risk & Low risk ${ }^{\mathrm{a}}$ & Low risk \\
\hline Liu 2012 [30] & Unclear risk & Unclear risk & Unclear risk & Low risk & Low risk & Unclear risk & Low risk \\
\hline $\begin{array}{l}\text { Tongyoo } 2016 \\
\text { [11] }\end{array}$ & Low risk & Low risk & Low risk & Low risk & Low risk & Unclear risk & Low risk \\
\hline $\begin{array}{l}\text { Tomazini } 2020 \\
\text { [12] }\end{array}$ & Low risk & Low risk & High risk $^{\mathrm{b}}$ & Low risk & Low risk & Low risk & High risk $^{\mathrm{d}}$ \\
\hline Villar 2020a [13] & Low risk & Low risk & High risk $^{\mathrm{b}}$ & Low risk & Low risk & Low risk & High risk $^{\mathrm{d}}$ \\
\hline
\end{tabular}

${ }^{a}$ We got information by author contact in Meduri [8] and Meduri [10]. Meduri [8] REPLY: Central randomization by a third party in order to conceal the allocation; Physicians and all medical personnel were blinded. Meduri [10] REPLY: The randomization is double blind and will remain blind throughout therapy to physicians, nursing care teams, research investigators, outcome assessor, participants and their family members. The primary objective of this prospective double blind, randomized clinical trial is to assess the effects of prolonged methylprednisolone therapy on the following response by days 7 and 28 of therapy: improvement in lung injury score, number of ventilator-free days, mortality

${ }^{\mathrm{b}}$ These studies did not use placebo in control group

${ }^{\mathrm{c}}$ Not planned outcomes in pre-published protocol

${ }^{\mathrm{d}}$ The study was stopped earlier than planned

The analysis of individual patients' data from RCTs showed that low-dose methylprednisolone reduced mortality and VFD compared to placebo, although this SR/MA did not compare each steroid regimen [32]. Prolonging any steroid was suggested to improve mortality of patients with ARDS regardless of the type of steroids [33]. In addition, recent
SR/MAs was demonstrated for early and longer steroids in patients with ARDS and its effectiveness on mortality was verified by synthesizing studies on low-dose methylprednisolone and dexamethasone [6]. One recent retrospective propensity-matched cohort study suggested that the pulsed methylprednisolone therapy worsened the 60-day mortality 
Table 3 NMA-SoF table

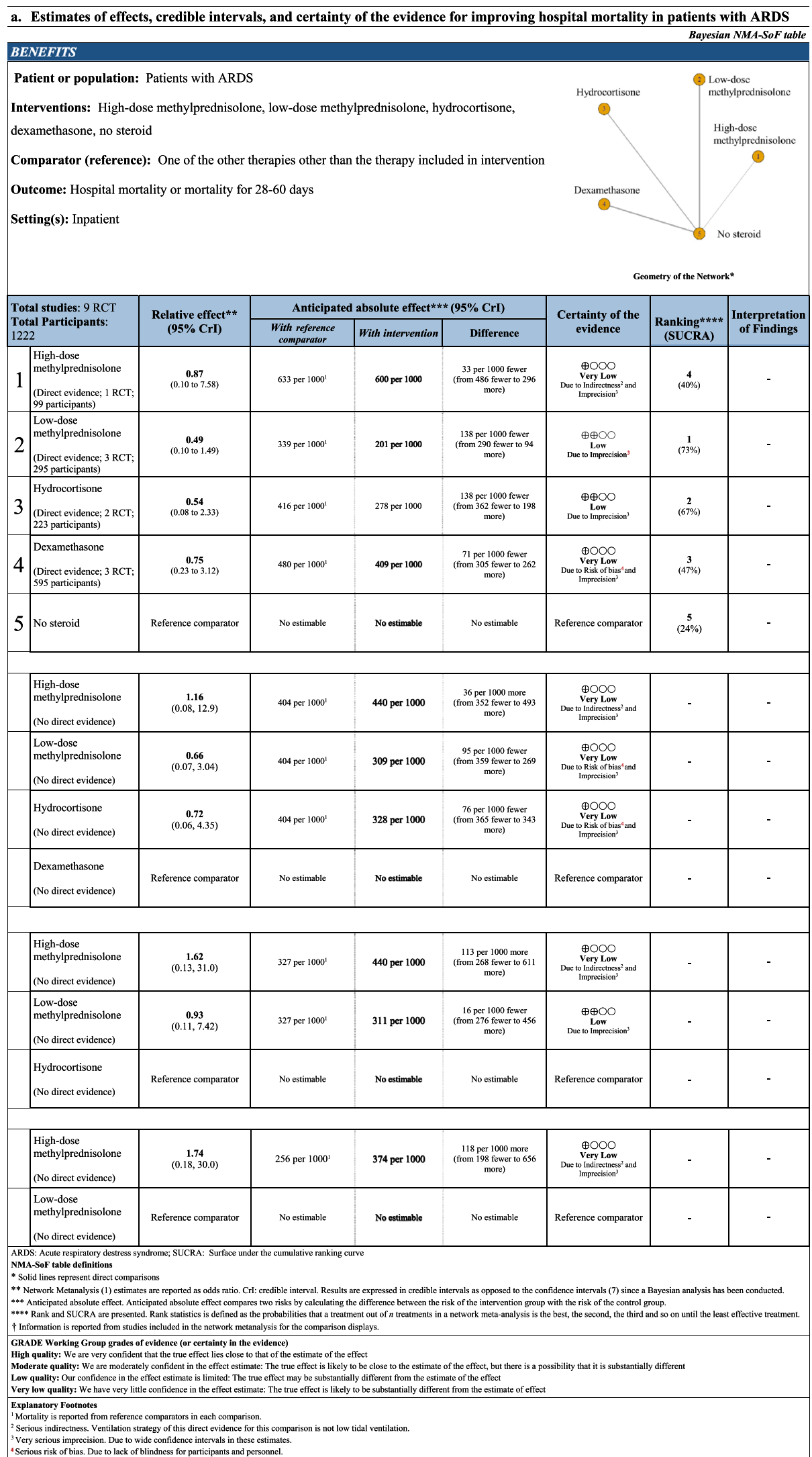


Table 3 (continued)

Patient or population: Patients with ARDS

Interventions: High-dose methylprednisolone, low-dose methylprednisolone, hydrocortisone, dexamethasone, no steroid

Comparator (reference): One of the other therapies other than the therapy included in intervention

Outcome: Incidence of infection

Setting(s): Inpatient

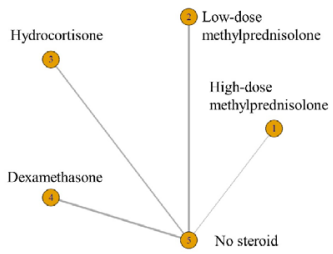

Geometry of the Network*

\begin{tabular}{|c|c|c|c|c|c|c|c|c|}
\hline \multirow{2}{*}{\multicolumn{2}{|c|}{$\begin{array}{l}\text { Total studies: } 9 \text { RCT } \\
\text { Total Participants: } \\
1222 \\
\end{array}$}} & \multirow{3}{*}{$\begin{array}{c}\begin{array}{c}\text { Relative effect } * * \\
\text { (95\% } \mathrm{CrI})\end{array} \\
\begin{array}{c}1.72 \\
(0.46 \text { to } 6.88)\end{array}\end{array}$} & \multicolumn{3}{|c|}{ Anticipated absolute effect $* * *(95 \% \mathrm{CrI})$} & \multirow{3}{*}{$\begin{array}{c}\begin{array}{c}\text { Certainty of the } \\
\text { evidence }\end{array} \\
\begin{array}{c}\oplus \circ 0 \bigcirc \\
\text { Very Low } \\
\text { Due to Indrectress' and } \\
\text { Imprecision }\end{array} \\
\end{array}$} & \multirow{3}{*}{\begin{tabular}{|c}
$\begin{array}{c}\text { Ranking**** } \\
\text { (SUCRA) }\end{array}$ \\
\\
5 \\
$(17 \%)$
\end{tabular}} & \multirow{3}{*}{$\begin{array}{c}\text { Interpretation } \\
\text { of Findings }\end{array}$} \\
\hline & & & \multirow{2}{*}{$\begin{array}{c}\begin{array}{c}\text { With reference } \\
\text { comparator }\end{array} \\
102 \text { per } 1000^{1}\end{array}$} & \multirow{2}{*}{\begin{tabular}{|c|} 
With intervention \\
163 per 1000
\end{tabular}} & \multirow{2}{*}{$\begin{array}{c}\text { Difference } \\
\begin{array}{c}61 \text { per } 1000 \text { fewer } \\
\text { (from } 52 \text { fewer to } 337 \\
\text { more) }\end{array}\end{array}$} & & & \\
\hline 1 & \begin{tabular}{|l|} 
High-dose \\
methylprednisolone \\
(Direct evidence; 1 RCT; \\
99 participants)
\end{tabular} & & & & & & & \\
\hline 2 & \begin{tabular}{|l|} 
Low-dose \\
methylprednisolone \\
$\begin{array}{l}\text { (Direct evidence; } 3 \text { RCT; } \\
\text { 295 participants) }\end{array}$ \\
\end{tabular} & $\begin{array}{c}\mathbf{0 . 5 6} \\
(0.30 \text { to } 1.10)\end{array}$ & 417 per $1000^{1}$ & 286 per 1000 & $\begin{array}{l}131 \text { per } 1000 \text { fewer } \\
\text { (from } 240 \text { fewer to } 23 \\
\text { morc) }\end{array}$ & $\begin{array}{c}\oplus \oplus \oplus \circ \\
\text { Moderate } \\
\text { Due to Imprecision" }\end{array}$ & $\underset{(88 \%)}{1}$ & - \\
\hline 3 & $\begin{array}{l}\text { Hydrocortisone } \\
\text { (Direct evidence; 2 RCT; } \\
223 \text { participants) }\end{array}$ & $\begin{array}{c}1.01 \\
(0.44102 .41)\end{array}$ & 186 per $1000^{1}$ & 188 per 1000 & $\begin{array}{l}2 \text { per } 1000 \text { more } \\
\text { (from } 95 \text { fewer to } 169 \\
\text { more) }\end{array}$ & $\begin{array}{c}\oplus \oplus \circ) \\
\begin{array}{c}\oplus \text { Low } \\
\text { Due to Imprecision }\end{array}\end{array}$ & $\underset{(42 \%)}{3}$ & - \\
\hline 4 & \begin{tabular}{|l|} 
Dexamethasone \\
(Direct evidence; 3 RCT; \\
595 participants)
\end{tabular} & $\begin{array}{l}0.77 \\
(0.43 \text { to } 1.32)\end{array}$ & 285 per $1000^{\prime}$ & 235 per 1000 & $\begin{array}{l}50 \text { per } 1000 \text { fewer } \\
\text { (from } 139 \text { fewer to } 60 \\
\text { more) }\end{array}$ & $\begin{array}{c}\oplus \circ O \bigcirc \\
\text { Very Low } \\
\text { Due to Risk of biass, } \\
\text { Imprecision }{ }^{2}\end{array}$ & $\underset{(67 \%)}{2}$ & - \\
\hline 5 & No steroid & Reference comparator & No cstimable & No estimable & No estimable & Reference comparator & $\begin{array}{c}4 \\
(37 \%)\end{array}$ & - \\
\hline & 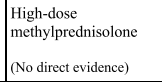 & $\begin{array}{c}2.26 \\
(0.55,10.2)\end{array}$ & 232 per $1000^{2}$ & 406 per 1000 & $\begin{array}{l}174 \text { per } 1000 \text { more } \\
\text { (from } 90 \text { fewer to } 523 \\
\text { more) }\end{array}$ & 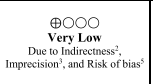 & - & - \\
\hline & \begin{tabular}{|l|} 
Low-dose \\
methylprednisolone \\
(No direct evidence)
\end{tabular} & $\begin{array}{c}\mathbf{0 . 7 4} \\
(0.32,1.77)\end{array}$ & 232 per $1000^{3}$ & 183 per 1000 & $\begin{array}{l}49 \text { per } 1000 \text { fewer } \\
\text { (from } 144 \text { fewer to } 116 \\
\text { morc) }\end{array}$ & 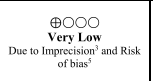 & - & - \\
\hline & $\begin{array}{l}\text { Hydrocortisone } \\
\text { (No direct evidence) }\end{array}$ & $\begin{array}{c}1.32 \\
(0.49,3.84)\end{array}$ & 232 per $1000^{1}$ & 285 per 1000 & $\begin{array}{l}53 \text { per } 1000 \text { more } \\
\text { (from } 103 \text { fewer to } 305 \\
\text { more) }\end{array}$ & 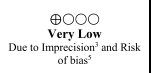 & - & - \\
\hline & $\begin{array}{l}\text { Dexamethasone } \\
\text { (No direct evidence) }\end{array}$ & Reference comparator & No estimable & No estimable & No estimable & Reference comparator & - & - \\
\hline & \begin{tabular}{|l|}
$\begin{array}{l}\text { High-dose } \\
\text { methylprednisolone } \\
\text { (No direct evidence) }\end{array}$ \\
\end{tabular} & $\begin{array}{c}1.73 \\
(0.33,8.45)\end{array}$ & 181 per $1000^{1}$ & 276 per 1000 & $\begin{array}{l}95 \text { per } 1000 \text { more } \\
\text { (from } 113 \text { fewer to } 468 \\
\text { more) }\end{array}$ & 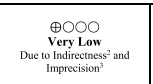 & - & - \\
\hline & \begin{tabular}{|l|} 
Low-dose \\
methylprednisolone \\
(No direct evidence)
\end{tabular} & $\begin{array}{c}\mathbf{0 . 5 6} \\
(0.19,1.60)\end{array}$ & 181 per $1000^{1}$ & 110 per 1000 & $\begin{array}{c}71 \text { per } 1000 \text { fewer } \\
\text { (from } 141 \text { fewer to } 80 \\
\text { more) }\end{array}$ & $\begin{array}{c}\oplus \oplus \circ \bigcirc \\
\text { Low } \\
\text { Dut to Imprecision }\end{array}$ & - & - \\
\hline & $\begin{array}{l}\text { Hydrocortisone } \\
\text { (No direct evidence) }\end{array}$ & Reference comparator & No estimable & No estimable & No estimable & Reference comparator & - & - \\
\hline & \begin{tabular}{|l|}
$\begin{array}{l}\text { High-dose } \\
\text { methylprednisolone }\end{array}$ \\
(No direct evidence)
\end{tabular} & $\begin{array}{c}3.06 \\
(0.70,14.1)\end{array}$ & 351 per $1000^{1}$ & 623 per 1000 & $\begin{array}{l}272 \text { per } 1000 \text { more } \\
\text { (from } 76 \text { fewer to } 533 \\
\text { morc) }\end{array}$ & 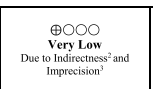 & & - \\
\hline & \begin{tabular}{|l|} 
Low-dose \\
methylprednisolone \\
(No direct evidence)
\end{tabular} & Reference comparator & No estimable & No estimable & No estimable & Reference comparator & & - \\
\hline & 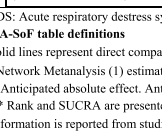 & $\begin{array}{l}\text { drome; SUCRA: Surface un } \\
\text { ions } \\
\text { are reported as odds ratio, } \\
\text { ipated absolute effect compa } \\
\text { Rank statistics is defined as } \\
\text { included in the network me }\end{array}$ & $\begin{array}{l}\text { cumulative rankin } \\
\text { dible interval. Resu } \\
\text { o risks by calculatin } \\
\text { obabilities that a trc } \\
\text { is for the comparisc }\end{array}$ & $\begin{array}{l}\text { expressed in credible i } \\
\text { difference between the } \\
\text { tout of } n \text { tractments in } \\
\text { llays. }\end{array}$ & $\begin{array}{l}\text { : k of the interention gr } \\
\text { network meta-analysis }\end{array}$ & $\begin{array}{l}\text { dence intervals (7) since a B } \\
\text { ith the risk of the contror gr } \\
\text { best, the sccond, the third an }\end{array}$ & $\begin{array}{l}\text { Bayesian analysis } \\
\text { roup. } \\
\text { nd so on until the }\end{array}$ & $\begin{array}{l}\text { been conducted. } \\
\text { teffcetive treatment. }\end{array}$ \\
\hline & $\begin{array}{l}\text { ADE Working Group grades } \\
\text { h quality: We are very confider } \\
\text { derate quality: We are moderat } \\
\text { quality: Our confidence in the } \\
\text { y low quality: We have very lit }\end{array}$ & $\begin{array}{l}\text { evidence (or certainty in th } \\
\text { hat the true effect lies close } \\
\text { y confident in the effect estin } \\
\text { ffect estimate is limited: The } \\
\text { confidence in the effect esti }\end{array}$ & $\begin{array}{l}\text { idence) } \\
\text { at of the estimate of th } \\
\text { : het true effect is like } \\
\text { effect may be substan } \\
\text { c: The true effect is lik }\end{array}$ & $\begin{array}{l}\text { frect } \\
\text { obe close to the estimate } \\
\text { be different from the estit } \\
\text { to be substantially differs }\end{array}$ & $\begin{array}{l}\text { f the effect, but there is a po } \\
\text { te of the effect } \\
\text { f rom the estimate of effect }\end{array}$ & ssibility that it is substantially & ifferent & \\
\hline & 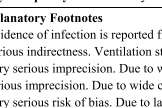 & $\begin{array}{l}\text { m refercence comparators in } \\
\text { tegy of this dircet evidence f } \\
\text { te confidence intervals in the } \\
\text { fidence intervals in these es } \\
\text { of blindness for participant }\end{array}$ & $\begin{array}{l}\text { omparison. } \\
\text { s comparison is not } 1 \mathrm{l} \\
\text { imates. } \\
\text { s. } \\
\text { onnel and outcome }\end{array}$ & al ventilation. & reporting. & & & \\
\hline
\end{tabular}


Table 3 (continued)

c. Estimates of effects, credible intervals, and certainty of the evidence for ventilator-free days in patients with ARDS

\begin{tabular}{|l}
\hline BENEFITS \\
Bayesian NMA-SoF table
\end{tabular}

Patient or population: Patients with ARDS

Interventions: Low-dose methylprednisolone, hydrocortisone, dexamethasone, no steroid

Comparator (reference): One of the other therapies other than the therapy included in intervention

Outcome: Ventilator-free days for 28 days

Setting(s): Inpatient

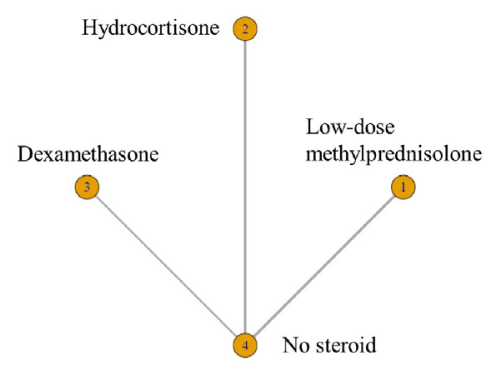

Geometry of the Network*

\begin{tabular}{|c|c|c|c|c|c|c|c|}
\hline \multirow{2}{*}{\multicolumn{2}{|c|}{$\begin{array}{l}\text { Total studies: } 7 \text { RCT } \\
\text { Total Participants: } 1094\end{array}$}} & \multirow{2}{*}{$\begin{array}{l}\text { Relative effect } \\
\text { (95\% CrI) }\end{array}$} & \multicolumn{2}{|c|}{ Anticipated absolute effect $(95 \% \mathrm{CrI})^{* *}$} & \multirow{2}{*}{$\begin{array}{l}\text { Certainty of } \\
\text { evidence }\end{array}$} & \multirow{2}{*}{$\begin{array}{c}\text { Ranking***} \\
\text { (SUCRA) }\end{array}$} & \multirow{2}{*}{$\begin{array}{l}\text { Interpretatio } \\
\mathbf{n} \text { of Findings }\end{array}$} \\
\hline & & & Assumed risk control & With intervention & & & \\
\hline 1 & $\begin{array}{l}\text { Low-dose } \\
\text { methylprednisolone } \\
\text { (Direct evidence; } 3 \text { RCT; } \\
295 \text { participants) }\end{array}$ & - & Study population & $\begin{array}{l}\text { The mean difference in increasing } \\
\text { VFDs was } 6.06 \text { higher ( } 2.5 \text { higher to } \\
10.5 \text { higher) }\end{array}$ & $\underset{\text { High }}{\oplus \oplus \oplus \oplus}$ & $\begin{array}{c}1 \\
(93 \%)\end{array}$ & - \\
\hline 2 & $\begin{array}{l}\text { Hydrocortisone } \\
\text { (Direct evidence; 2 RCT; } \\
223 \text { participants) }\end{array}$ & - & Study population & $\begin{array}{l}\text { The mean difference in increasing } \\
\text { VFDs was } 2.10 \text { higher ( } 3.15 \text { lower to } \\
7.09 \text { higher) }\end{array}$ & $\begin{array}{c}\oplus \oplus \bigcirc \bigcirc \\
\text { Low } \\
\text { Due to Imprecision }\end{array}$ & $\begin{array}{c}\mathbf{3} \\
(39 \%)\end{array}$ & - \\
\hline 3 & $\begin{array}{l}\text { Dexamethasone } \\
\text { (Direct evidence; } 2 \text { RCT; } \\
576 \text { participants) }\end{array}$ & - & Study population & $\begin{array}{l}\text { The mean difference in increasing } \\
\text { VFDs was } 3.64 \text { higher ( } 0.56 \text { lower to } \\
7.83 \text { higher) }\end{array}$ & $\begin{array}{c}\oplus \bigcirc \bigcirc \bigcirc \\
\begin{array}{c}\text { Very Low } \\
\text { Due to Imprecision } \\
\text { of bias }^{2}\end{array} \\
\text { and Risk }\end{array}$ & $\begin{array}{c}\mathbf{2} \\
(62 \%)\end{array}$ & - \\
\hline 4 & No steroid & $\begin{array}{l}\text { Reference } \\
\text { comparator }\end{array}$ & No estimable & No estimable & Reference comparator & $\begin{array}{c}4 \\
(7 \%)\end{array}$ & - \\
\hline & $\begin{array}{l}\text { Low-dose } \\
\text { methylprednisolone } \\
\text { (No direct evidence) }\end{array}$ & - & Study population & $\begin{array}{l}\text { The mean difference in increasing } \\
\text { VFDs was } 2.40 \text { higher ( } 2.87 \text { lower to } \\
8.70 \text { higher) }\end{array}$ & $\begin{array}{c}\oplus \bigcirc \bigcirc \bigcirc \\
\begin{array}{c}\text { Very Low } \\
\text { Due to Imprecision } \\
\text { of bias }^{2}\end{array} \\
\end{array}$ & & \\
\hline & $\begin{array}{l}\text { Hydrocortisone } \\
\text { (No direct evidence) }\end{array}$ & - & Study population & $\begin{array}{l}\text { The mean difference in increasing } \\
\text { VFDs was } 1.54 \text { lower ( } 8.34 \text { lower to } \\
4.87 \text { higher) }\end{array}$ & $\begin{array}{c}\oplus \bigcirc \bigcirc \bigcirc \\
\text { Very Low } \\
\begin{array}{c}\text { Due to Imprecision } \\
\text { of bias }^{2}\end{array} \\
\end{array}$ & & \\
\hline & $\begin{array}{l}\text { Dexamethasone } \\
\text { (No direct evidence) }\end{array}$ & $\begin{array}{l}\text { Reference } \\
\text { comparator }\end{array}$ & No estimable & No estimable & Reference comparator & & \\
\hline & $\begin{array}{l}\text { Low-dose } \\
\text { methylprednisolone } \\
\text { (No direct evidence) }\end{array}$ & - & Study population & $\begin{array}{l}\text { The mean difference in increasing } \\
\text { VFDs was } 3.99 \text { higher ( } 1.90 \text { lower to } \\
11.1 \text { higher) }\end{array}$ & $\begin{array}{c}\oplus \oplus \oplus \bigcirc \\
\text { Moderate } \\
\text { Due to Imprecision }\end{array}$ & & \\
\hline & $\begin{array}{l}\text { Hydrocortisone } \\
\text { (No direct evidence) }\end{array}$ & $\begin{array}{l}\text { Reference } \\
\text { comparator }\end{array}$ & No estimable & No estimable & Reference comparator & & \\
\hline \multicolumn{8}{|c|}{$\begin{array}{l}\text { ARDS: Acute respiratory destress syndrome; VFDs: Ventilator-free days; MD: Mean difference; SUCRA: Surface under the cumulative ranking curve } \\
\text { NMA-SoF table definitions } \\
\text { * Lines in the network graphic represent direct comparisons } \\
\text { ** Estimates are reported as mean difference and credible interval (CrI). Results are expressed in credible intervals as opposed to the confidence intervals since a Bayesian analysis has been conducted. } \\
\text { *** Rank and SUCRA are presented. Rank statistics is defined as the probabilities that a treatment out of } n \text { treatments in a network meta-analysis is the best, the second, the third and so on until the least effective } \\
\text { treatment. }\end{array}$} \\
\hline \multicolumn{8}{|c|}{$\begin{array}{l}\text { GRADE Working Group grades of evidence (or certainty in the evidence) } \\
\text { High quality: We are very confident that the true effect lies close to that of the estimate of the effect } \\
\text { Moderate quality: We are moderately confident in the effect estimate: The true effect is likely to be close to the estimate of the effect, but there is a pos } \\
\text { Low quality: Our confidence in the effect estimate is limited: The true effect may be substantially different from the estimate of the effect } \\
\text { Very low quality: We have very little confidence in the effect estimate: The true effect is likely to be substantially different from the estimate of effect }\end{array}$} \\
\hline \multicolumn{8}{|c|}{$\begin{array}{l}\text { Explanatory Footnotes. } \\
{ }^{1} \text { Very serious imprecision. Due to wide confidence intervals in these estimates, defined two VFDs as clinically meaning deference of VFDs. } \\
2 \text { Very serious risk of bias. Due to lack of blindness for participants and personnel, and unplanned discontinuation of trial. } \\
{ }^{3} \text { Serious imprecision. Due to wide confidence intervals in these estimates, defined two VFDs as clinically meaning deference of VFDs. }\end{array}$} \\
\hline
\end{tabular}


Fig. 3 Rank probabilities in the network meta-analysis
A Hospital mortality

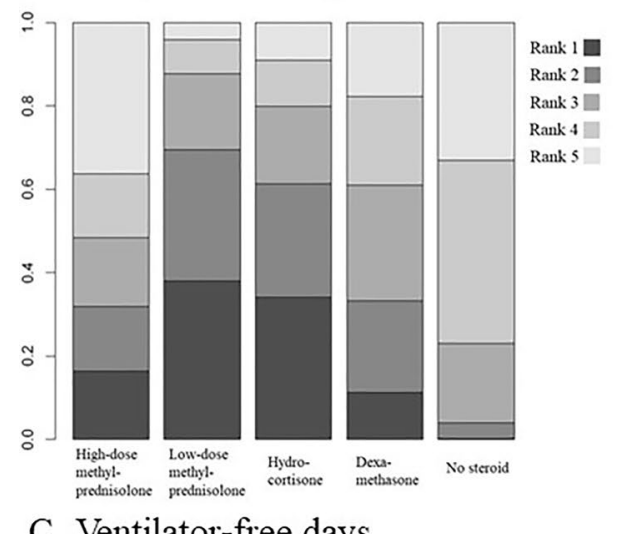

C Ventilator-free days

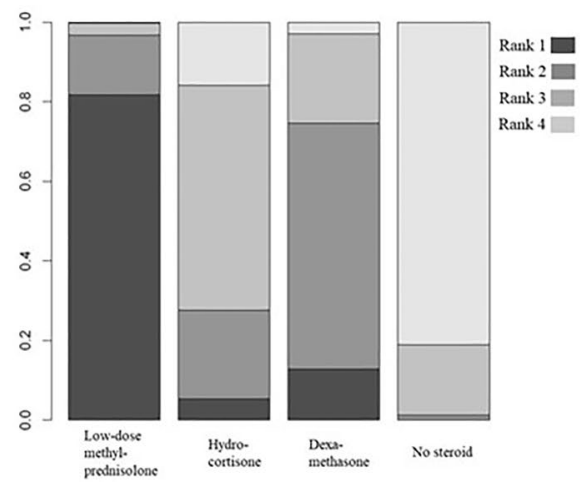

B Incidence of infection

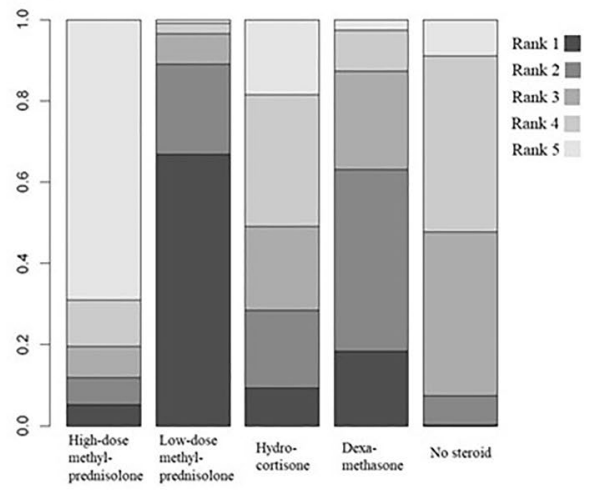

and VFD [18]. In contrast to previous SR/MAs, our direct pairwise comparisons show that any of the steroids were not associated with reducing hospital mortality and incidence of infection compared with no steroid. Based on these results, any type of steroids might not build up a steadfast position.

Though previous studies provided results of a pairwise comparison with placebo, we created indirect estimates of comparisons among steroids by NMA and verified estimates of hospital mortality, the incidence of infection, and VFD among each steroid. This NMA for patients with ARDS revealed that low-dose methylprednisolone or hydrocortisone relative to dexamethasone may reduce hospital mortality (95 per 1000 patients fewer, 76 per 1000 patients fewer, respectively), high-dose methylprednisolone relative to hydrocortisone may increase hospital mortality (113 per 1000 patients more), and high-dose methylprednisolone relative to low-dose methylprednisolone may increase hospital mortality (118 per 1000 patients more). Low-dose methylprednisolone relative to hydrocortisone may reduce incidence of infection (71 per 1000 patients fewer), while high-dose methylprednisolone relative to other steroids may increase incidence of infection (95-272 per 1000 patients more). Low-dose methylprednisolone relative to hydrocortisone and dexamethasone may increase VFD (6.06, 2.40 higher, respectively). In addition, the rank probability showed that low-dose methylprednisolone may be the optimal treatment, whereas high-dose methylprednisolone and no steroid may be the inferior to other treatment in terms of hospital mortality, incidence of infection, and VFD. Though the evidences were uncertain, considering these results and point estimates, our NMA suggested that the effect of steroids on outcome vary depending on the types of steroids.

Our NMA has several limitations. We could not use EMBASE for our database search. However, we consider studies that were included as appropriate, as we manually searched the reference list of the included articles and their reference lists and checked previous SRs/MAs. Although we performed an NMA, each comparison included only a few studies. In addition, NMA for VFD did not include studies using high-dose methylprednisolone. Conventional therapy strategies besides steroids may vary among eligible studies. In particular, compliance with the low tidal ventilation strategy, which was the strategy to improve mortality, was low in 1999 or earlier. Though the definition of infection was not reported in some eligible studies and was discrepant between studies, the definition of each study conformed to the general criteria. There may be an unexplained heterogeneity among eligible studies other than different definitions of infection because a placebo was not used in studies on dexamethasone. However, we made efforts to minimize heterogeneity by including patients with mechanical ventilation and 
checking age, diagnosis criteria, and etiology. Finally, we could not deny the possibility that not only the types of steroids but also the duration of administration might affect our results. We have defined the types and protocols of steroids based on previous studies, as previous RCTs did not verify different durations among steroids; however, we could not stratify results by the duration of steroids. Considering past studies, as low-dose methylprednisolone was administered the longest duration among the types of steroids, favorable outcomes of low-dose methylprednisolone may be obtained. Therefore, we could not draw conclusions on the optimal steroid agent. Further studies including these above studies must confirm our results.

In conclusion, our results indicate that the effect of steroids on outcome might vary depending on the type of steroids in ARDS patients. Further studies are needed to identify the optimal type and dosage.

Supplementary Information The online version contains supplementary material available at https://doi.org/10.1007/s00540-021-03016-5.

Acknowledgements We greatly appreciate that Dr. Jesús Villar, Prof. Djillai Annane and Prof. G. Umberto Meduri provided additional information about their studies.

Funding Not applicable.

Data availability The datasets analyzed during the current network meta-analysis are available from the corresponding author upon reasonable request.

\section{Declarations}

Conflict of interest All the authors declare that they have no conflicts of interest.

\section{References}

1. Villar J, Blanco J, Añón JM, Santos-Bouza A, Blanch L, Ambrós A, Gandía F, Carriedo D, Mosteiro F, Basaldúa S, Fernández RL, Kacmarek RM, on behalf of the AN. The ALIEN study: incidence and outcome of acute respiratory distress syndrome in the era of lung protective ventilation. Intensive Care Med. 2011;37(12):1932-41.

2. Bellani G, Laffey JG, Pham T, Fan E, Brochard L, Esteban A, Gattinoni L, van Haren F, Larsson A, McAuley DF, Ranieri M, Rubenfeld G, Thompson BT, Wrigge H, Slutsky AS, Pesenti A. Epidemiology, patterns of care, and mortality for patients with acute respiratory distress syndrome in intensive care units in 50 countries. JAMA. 2016;315(8):788-800.

3. Meduri GU, Muthiah MP, Carratù P, Eltorky M, Chrousos GP. Nuclear factor-KB- and glucocorticoid receptor $\alpha$ - mediated mechanisms in the regulation of systemic and pulmonary inflammation during sepsis and acute respiratory distress syndrome. NeuroImmunoModulation. 2005;12(6):321-38

4. Meduri GU, Annane D, Chrousos GP, Marik PE, Sinclair SE. Activation and regulation of systemic inflammation in
ARDS: Rationale for prolonged glucocorticoid therapy. Chest. 2009;136(6):1631-43.

5. Chaudhuri D, Sasaki K, Karkar A, Sharif S, Lewis K, Mammen MJ, Alexander P, Ye Z, Lozano LEC, Munch MW, Perner A, Du B, Mbuagbaw L, Alhazzani W, Pastores SM, Marshall J, Lamontagne F, Annane D, Meduri GU, Rochwerg B. Corticosteroids in COVID-19 and non-COVID-19 ARDS: a systematic review and meta-analysis. Intensive Care Med. 2021;47(5):521-37.

6. Hirano Y, Madokoro S, Kondo Y, Okamoto K, Tanaka H. Corticosteroid treatment for early acute respiratory distress syndrome: a systematic review and meta-analysis of randomized trials. J Intensive Care. 2020;8(1):91.

7. Bernard GR, Luce JM, Sprung CL, Rinaldo JE, Tate RM, Sibbald WJ, Kariman K, Higgins S, Bradley R, Metz CA. Highdose corticosteroids in patients with the adult respiratory distress syndrome. N Engl J Med. 1987;317(25):1565-70.

8. Meduri GU, Headley AS, Golden E, Carson SJ, Umberger RA, Kelso T, Tolley EA. Effect of prolonged methylprednisolone therapy in unresolving acute respiratory distress syndrome: a randomized controlled trial. JAMA. 1998;280(2):159-65.

9. Steinberg KP, Hudson LD, Goodman RB, Hough CL, Lanken PN, Hyzy R, Thompson BT, Ancukiewicz M. Efficacy and safety of corticosteroids for persistent acute respiratory distress syndrome. N Engl J Med. 2006;354(16):1671-84.

10. Meduri GU, Golden E, Freire AX, Taylor E, Zaman M, Carson SJ, Gibson M, Umberger R. Methylprednisolone infusion in early severe ARDS: results of a randomized controlled trial. Chest. 2007;131(4):954-63.

11. Tongyoo S, Permpikul C, Mongkolpun W, Vattanavanit V, Udompanturak S, Kocak M, Meduri GU. Hydrocortisone treatment in early sepsis-associated acute respiratory distress syndrome: results of a randomized controlled trial. Crit Care. 2016;20(1):329.

12. Tomazini BM, Maia IS, Cavalcanti AB, Berwanger O, Rosa RG, Veiga VC, Avezum A, Lopes RD, Bueno FR, Silva MVAO, Baldassare FP, Costa ELV, Moura RAB, Honorato MO, Costa AN, Damiani LP, Lisboa T, Kawano-Dourado L, Zampieri FG, Olivato GB, Righy C, Amendola CP, Roepke RML, Freitas DHM, Forte DN, Freitas FGR, Fernandes CCF, Melro LMG, Junior GFS, Morais DC, Zung S, Machado FR, Azevedo LCP, Investigators CC-BI. Effect of dexamethasone on days alive and ventilatorfree in patients with moderate or severe acute respiratory distress syndrome and COVID-19: the CoDEX randomized clinical trial. JAMA. 2020;324(13):1307-16.

13. Villar J, Ferrando C, Martínez D, Ambrós A, Muñoz T, Soler JA, Aguilar G, Alba F, González-Higueras E, Conesa LA, MartínRodríguez C, Díaz-Domínguez FJ, Serna-Grande P, Rivas R, Ferreres J, Belda J, Capilla L, Tallet A, Añón JM, Fernández RL, González-Martín JM. Dexamethasone treatment for the acute respiratory distress syndrome: a multicentre, randomised controlled trial. Lancet Respir Med. 2020;8(3):267-76.

14. The PRISMA Extension Statement for Reporting of Systematic Reviews Incorporating Network Meta-analyses of Health Care Interventions: checklist and explanations. Ann Intern Med. 2015;162(11):777-84.

15. Bernard GR, Artigas A, Brigham KL, Carlet J, Falke K, Hudson L, Lamy M, Legall JR, Morris A, Spragg R. The American-European Consensus Conference on ARDS. Definitions, mechanisms, relevant outcomes, and clinical trial coordination. Am J Respir Crit Care Med. 1994;149(3 pt 1):818-24.

16. Ranieri VM, Rubenfeld GD, Thompson BT, Ferguson ND, Caldwell E, Fan E, Camporota L, Slutsky AS. Acute respiratory distress syndrome: the Berlin Definition. JAMA. 2012;307(23):2526-33.

17. Tang BM, Craig JC, Eslick GD, Seppelt I, McLean AS. Use of corticosteroids in acute lung injury and acute respiratory distress 
syndrome: a systematic review and meta-analysis. Crit Care Med. 2009;37(5):1594-603.

18. Takaki M, Ichikado K, Kawamura K, Gushima Y, Suga M. The negative effect of initial high-dose methylprednisolone and tapering regimen for acute respiratory distress syndrome: a retrospective propensity matched cohort study. Crit Care. 2017;21(1):135.

19. Annane D, Pastores SM, Rochwerg B, Arlt W, Balk RA, Beishuizen A, Briegel J, Carcillo J, Christ-Crain M, Cooper MS, Marik PE, Umberto Meduri G, Olsen KM, Rodgers SC, Russell JA, Van den Berghe G. Guidelines for the diagnosis and management of critical illness-related corticosteroid insufficiency (CIRCI) in critically ill patients (part I): Society of Critical Care Medicine (SCCM) and European Society of Intensive Care Medicine (ESICM) 2017. Crit Care Med. 2017;45(12):2078-88.

20. Lewis SR, Pritchard MW, Thomas CM, Smith AF. Pharmacological agents for adults with acute respiratory distress syndrome. Cochrane Database Syst Rev. 2019;7(7): Cd004477.

21. Mammen MJ, Aryal K, Alhazzani W, Alexander PE. Corticosteroids for patients with acute respiratory distress syndrome: a systematic review and meta-analysis of randomized trials. Pol Arch Intern Med. 2020;130(4):276-86.

22. Zayed Y, Barbarawi M, Ismail E, Samji V, Kerbage J, Rizk F, Salih M, Bala A, Obeid M, Deliwala S, Demian S, Al-Sanouri I, Reddy R. Use of glucocorticoids in patients with acute respiratory distress syndrome: a meta-analysis and trial sequential analysis. J Intensive Care. 2020;8(1):43.

23. H Higgins JPT, Thomas J, Chandler J, Cumpston M, Li T, Page M, Welch VA (editors). Cochrane handbook for systematic reviews of interventions, 2nd edn. Chichester: Wiley; 2019.

24. Dias S, Welton NJ, Caldwell DM, Ades AE. Checking consistency in mixed treatment comparison meta-analysis. Stat Med. 2010;29(7-8):932-44.

25. Salanti G, Ades AE, Ioannidis JP. Graphical methods and numerical summaries for presenting results from multiple-treatment meta-analysis: an overview and tutorial. J Clin Epidemiol. 2011;64(2):163-71.

26. Puhan MA, Schünemann HJ, Murad MH, Li T, BrignardelloPetersen R, Singh JA, Kessels AG, Guyatt GH. A GRADE Working Group approach for rating the quality of treatment effect estimates from network meta-analysis. BMJ Br Med J. 2014;349: g5630.

27. Brignardello-Petersen R, Bonner A, Alexander PE, Siemieniuk RA, Furukawa TA, Rochwerg B, Hazlewood GS, Alhazzani W, Mustafa RA, Murad MH, Puhan MA, Schünemann HJ, Guyatt GH. Advances in the GRADE approach to rate the certainty in estimates from a network meta-analysis. J Clin Epidemiol. 2018;93:36-44.

28. Yepes-Nuñez JJ, Li SA, Guyatt G, Jack SM, Brozek JL, Beyene J, Murad MH, Rochwerg B, Mbuagbaw L, Zhang Y, Flórez ID,
Siemieniuk RA, Sadeghirad B, Mustafa R, Santesso N, Schünemann HJ. Development of the summary of findings table for network meta-analysis. J Clin Epidemiol. 2019;115:1-13.

29. Meduri GU, Tolley EA, Chinn A, Stentz F, Postlethwaite A. Procollagen types I and III aminoterminal propeptide levels during acute respiratory distress syndrome and in response to methylprednisolone treatment. Am J Respir Crit Care Med. 1998;158(5):1432-41.

30. Liu L, Li J, Huang YZ, Liu SQ, Yang CS, Guo FM, Qiu HB, Yang Y. The effect of stress dose glucocorticoid on patients with acute respiratory distress syndrome combined with critical illnessrelated corticosteroid insufficiency. Zhonghua Nei Ke Za Zhi. 2012;51(8):599-603.

31. Villar J, Añón JM, Ferrando C, Aguilar G, Muñoz T, Ferreres J, Ambrós A, Aldecoa C, Suárez-Sipmann F, Thorpe KE, Jüni P, Slutsky AS, Ferrando C, Mellado-Artigas R, Fernández J, Hernández M, Castellá M, Castro P, Badia JR, Aguilar G, Carbonell JA, Badenes R, Tornero C, Ferreres J, Blasco ML, Carbonell N, Serrano A, Juan M, Gómez-Herreras JI, López ML, Ambrós A, Martín C, del Campo R, Puig-Bernabeu J, Ferrer C, de Andrés J, Muñoz T, Serna-Grande P, Tamayo G, Martínez-Ruíz A, BilbaoVillasante I, Villar J, Fernández RL, Calvo CP, Vidal Á, Añón JM, Figueira JC, Asensio MJ, Maseda E, Suárez-Sipmann F, Ramasco F, Varela-Durán M, Díaz-Parada P, Trenado-Álvarez J, Fernández MM, Aldecoa C, Rico-Feijoo J, Fernández L, Sánchez-Ballesteros J, Blanco-Schweizer P, Martínez D, Soler JA, Slutsky AS, Jüni P, Thorpe KE, Thomas R, Wysocki K, de Verno P, Lakhanpal G, Juando-Prats C, the D-CN. Efficacy of dexamethasone treatment for patients with the acute respiratory distress syndrome caused by COVID-19: study protocol for a randomized controlled superiority trial. Trials. 2020;21(1):717.

32. Meduri GU, Bridges L, Shih M-C, Marik PE, Siemieniuk RAC, Kocak M. Prolonged glucocorticoid treatment is associated with improved ARDS outcomes: analysis of individual patients' data from four randomized trials and trial-level meta-analysis of the updated literature. Intensive Care Med. 2016;42(5):829-40.

33. Villar J, Confalonieri M, Pastores SM, Meduri GU. Rationale for prolonged corticosteroid treatment in the acute respiratory distress syndrome caused by coronavirus disease 2019. Crit Care Explor. 2020;2(4): e0111.

Publisher's Note Springer Nature remains neutral with regard to jurisdictional claims in published maps and institutional affiliations. 